Amateur Sources Breaking the News, Meta Sources Authorizing the News of Gaddafi's Death

New Patterns of Journalistic Information Gathering and Dissemination in the Digital Age

Mortensen, Mette; Kristensen, Nete Nørgaard

Published in:

Digital Journalism

DOI:

$10.1080 / 21670811.2013 .790610$

Publication date:

2013

Document version

Peer reviewed version

Citation for published version (APA):

Mortensen, M., \& Kristensen, N. N. (2013). Amateur Sources Breaking the News, Meta Sources Authorizing the News of Gaddafi's Death: New Patterns of Journalistic Information Gathering and Dissemination in the Digital Age . Digital Journalism, 1(3), 352-367. https://doi.org/10.1080/21670811.2013.790610 


\section{AMATEUR SOURCES BREAKING THE NEWS, METASOURCES AUTHORIZING THE NEWS OF GADDAFI'S DEATH}

By Nete Nørgaard Kristensen and Mette Mortensen, University of Copenhagen.

ABSTRACT: This article takes its point of departure in the thesis that today's global, digitalized and convergent media environment has promoted new patterns of information gathering and dissemination within journalism, and war journalism in particular, which involve changing forms and various degrees of interplay between elite and non-elite sources as well as media professionals and amateur sources. On account of their proximity to unfolding events, amateur sources often break the news by means of raw and fragmented bits of visual and verbal information. Elite sources rarely possess the same exclusive access to information from war zones, but are instead brought in to comment on, validate and grant legitimacy to amateur sources as a form of explicit source criticism that we would like to term metasourcing. This new pattern of information gathering and sourcing within war reporting manifests itself most clearly in cases of major international news events, which render visible the multitude of sources and the speed of information production and distribution. $A$ recent example is the capture and subsequent death of Muammar Gaddafi in October 2011. Based on quantitative and qualitative analyses of the sources included by selected newspapers to report on this event, the current article investigates the following research questions: Which types of sources are brought into play in the news coverage of Gaddafi's death, and which forms of interplay between sources in today's globalized and convergent media landscape are indicated by this case? 


\section{Keywords}

amateur images, amateur sources, breaking news, death of Gaddafi, elite sources, global media, metasourcing, war journalism

\section{Introduction}

War reporting has attracted scholarly attention as a branch of journalism undergoing major changes with the emergence of digital media, especially concerning the availability of sources and the gathering of information. The access to manifold and diverse digital sources of information has opened new opportunities for seeking out and researching stories. As scholars in this field have emphasized, the digital accessibility of sources, and amateur sources in particular, contrasts sharply with the traditional restrictions encountered by war journalism in the form of tight news management and censorship by belligerent nations, along with obstacles related to gaining entry to and reporting from the combat zone (e.g., Carruthers [2000] 2011; Matheson and Allan 2009; Mortensen 2012; Seib 2007). However, skepticism has also been voiced about the ability of digital media to democratize war reporting by empowering more sources. According to Robinson et al. (2010), for example, the empowerment argument often relies on random analysis, as opposed to the conclusion reached by systematic studies that elite sources still dominate.

Instead of arguing for the supremacy of one type of source over the other in war reporting, this article takes its point of departure from the thesis that today's global, digitized and convergent media environment has promoted new patterns of information gathering and dissemination within 
journalism, which involve changing forms and various degrees of interplay between elites and nonelites, media professionals and amateurs. The prominence of amateur sources such as eyewitness pictures in war reporting means that elite sources are assigned new roles and functions. On account of their proximity to unfolding events, amateur sources often break the news by means of raw and fragmented bits of visual and verbal information. Elite sources rarely possess the same exclusive access to information, but are instead brought in by news media to perform a practice that we would like to term metasourcing. With this concept, we refer to a sourcing pattern, whereby elite sources are included in the news coverage to comment on, validate and grant legitimacy to non-elite, amateur sources as a form of explicit source criticism.

This new type of information gathering and sourcing within war reporting manifests itself most clearly in cases of major international news events, which render visible the speed and multitude of sources. One recent example is the capture and subsequent death of Libya's ruler of 42 years, Muammar Gaddafi on 20 October 2011. This not only constituted an important political and historical event to the international community; it also represented a clear-cut instance of breaking news to the international media as a sensational, intense and sudden occurrence taking dramatic new turns in the course of a short time. The news media reported on the event extensively and minutely, at first primarily by using the continuous flow of amateur visuals created and distributed by participants in and/or eyewitnesses to the seizure and killing, but later by deploying and combining a variety of sources.

Based on quantitative and qualitative analyses of the sources included by selected newspapers to report on the death of Gaddafi, this article investigates the following research questions: which types 
of sources are brought into play in the news coverage of Gaddafi's death, and which forms of interplay between sources in today's globalized and convergent media landscape are indicated by this case? In the article, we first establish a theoretical framework for understanding the current changes to information gathering and dissemination in journalism by presenting our demarcation and interpretation of essential aspects of the existing research on sources and new media. This serves as a point of departure for critical engagement with the particular challenges and opportunities for war journalism arising from the abundance of non-conventional sources, especially amateur visuals. Second, we introduce the methodology behind a content analysis of the news coverage of the death of Gaddafi. Third, the major findings of this analysis are presented, complemented by a textual analysis of selected articles. The quantitative part identifies the most dominating types of sources, while the qualitative part analyzes their role in the media coverage. Whereas the quantitative analysis indicates the supremacy of elite sources, the qualitative analysis challenges this finding by disclosing the distinctive roles assigned to elite and amateur sources: with first-hand access to the scenes of the event, non-elite, amateur sources constitute the pivotal point of the news coverage. Elite sources, on the other hand, are included as part of a metasourcing strategy by commenting on, verifying and legitimizing the visual and verbal information provided by the amateurs, and, in so doing, establishing a historical and political framework for understanding this breaking news event. Fourth and finally, we conclude on metasourcing and draw a perspective to the related term metacoverage.

\section{New Media, New Sources}

We apply an inclusive notion of sources in order to grasp the diversity of actors and materials that 
shape the stream of information entering today's globalized and converging media. Primarily, we distinguish between two overall types of news sources: "source actors" (Couldry 2010) and "source materials". Source actors are normally individuals who reside outside media institutions. They provide first-hand information, eyewitness accounts, expertise, etc., in order for the journalist to report in a balanced and adequate manner based on relevant, available facts and information. Source materials are typically visual footage, written documents, archival material, etc., which may be cited explicitly, used for illustration or drawn on implicitly for background information.

In the narration and rhetorical framing of the story, journalists usually quote or refer to news sources as an essential and explicit part of the reporting. Journalism favors named sources willing to vouch publicly for the conveyed information and materials. However, anonymous sources also represent a common and important means of gathering information of public interest (Carlson 2011), even though their agenda may be difficult to decipher. Inasmuch as source actors typically represent particular interests and offer particular accounts of events, just as source materials may be closely connected to and promoted by specific actors or agendas, journalism studies have recurrently raised the question of which sources define and frame the news, typically distinguishing between elite and non-elite sources, i.e., between those who represent political, economical or military power and those who do not (e.g., Davis 2009; Schlesinger 1990).

Research into journalism and news sources has discussed the opportunities and especially the obstacles engendered by the rise of digital media (for overviews, see, e.g., Franklin and Carlson 2011; Mitchelstein and Boczkowski 2009; Philips 2010). More sources and source materials are becoming available to both journalists and audiences due to new media technologies, fostering source 
competition and potentially enabling alternative reports of events, which call into question the framing by institutionalized elites and institutionalized news media. However, the multiplicity, speed and accessibility of sources for journalists to monitor, investigate and critically approach come with the cost of information overload along with persistent difficulties with regard to verification. Usergenerated source materials in particular put professional journalism to the test because they are produced and disseminated outside the framework of established media institutions by individuals who may not be familiar with and/or obliged to follow the guidelines of professional journalism, for example, when it comes to confirming or validating information. Combined with continuous deadlines, this leaves little time for journalists to check their sources and information properly, which may ultimately influence the quality, thoroughness and originality of the news content. Research has therefore debated the actual deployment of user-generated content in professional journalism and found that not only audiences are skeptical about user-generated content as source material (Bergström 2011), but also professional journalists, who choose to rely on well-known, trustworthy sources and traditional routines for gathering information (e.g., Philips 2010). Scholars have similarly argued that user-generated content has revitalized the journalist's role as gatekeeper (e.g., Sjøvaag 2011), and that journalists employ user-generated content as a source like any other source fitted into the established professional practices (Williams, Wardle, and Wahl-Jorgensen 2011). Tuchman's (1973) concept of "routinizing the unexpected" thus still applies (e.g., Hartley 2011), despite-or because of-digital technologies facilitating multifarious sources and source materials.

This expansion of source actors and source materials accentuates the general tendency in journalism of ordinary people, citizens or "amateurs" as common news sources (De Keyser, Raeymaeckers, and 
Paulussen 2011). Among other things, they become representatives of a symbolic public and shared experiences or values - oftentimes despite their lack of genuine representational significance (Kunelius and Renvall 2010). Amateur sources contribute to the dissolving of professional boundaries in journalism and mix the roles of journalists and sources when, potentially, everybody may become reporters of events (e.g., Deuze 2007; Mitchelstein and Boczkowski 2009), and, conversely, the news media increasingly use their own or other media's reporters as sources in a circuit of self-referencing (e.g., Deuze 2008). The quantity and speed of information as well as the blurred characteristics of the professional journalist in the digital age challenge one of the backbones of journalism practice, namely source criticism, i.e., the continuous effort to verify information by consulting a multitude of relevant and reliable sources.

The considerable changes in the amount and character of sources pushing information into the media circuit threaten to dissolve the very notion of "a source" from within. For example, creators of usergenerated source materials may, as producers of media content, be termed "amateurs", regardless of whether they are ordinary citizens, participants or even institutional elites. We have chosen nonetheless to maintain the common vocabulary of source actors and source materials, because the heterogeneity currently contained within these expressions reflects the heterogeneity of the digital information flow, which journalists have to rely on and deal with. In the current context, the concept of "source" is further complicated by the manner in which the transformation of source patterns takes place along two intersecting axes: the axis of elites/non-elites and the axis of professionals/amateurs. Non-elite sources come to play an increasingly significant role as news sources that may challenge elite sources' framing of events. At the same time, amateurs situated 
outside a media institutional structure come to test the professional norms of journalism. Of special interest to this article is the presence and contributions of actors, which may, on the face of it, be perceived as both non-elite and amateur sources.

\section{Amateur Images as Sources in War Reporting}

In discussions on journalism and news sources in the digital age, war reporting constitutes a special case in point. Debates are ongoing as to whether the availability of information from areas of war and conflict has essentially changed with the advent of new technologies and distributive platforms. Even though studies on journalists and sources have contested the idea of specific elites being primary definers and structural power relationships thus defining the news (e.g., Davis 2009; Schlesinger 1990), some of the research into war reporting specifically has revealed that the news media tend to give preference to elite sources, especially those affiliated with the military and the government (e.g., Dimitrova and Strömbäck 2005; Kristensen and Ørsten 2007; Robinson et al. 2010). Military and political elites represent power and control access to information during wartime, e.g., by embedding journalists or arranging press conferences as the main platform for communication. This naturally limits the media's opportunities to test the information and the frames presented by military and political elite sources (e.g., Robinson et al. 2010). By contrast, other research has contended that prolific and easily available digital technologies have provided war reporting with new avenues (e.g., Carruthers [2000] 2011; Matheson and Allan 2009; Mortensen 2012; Seib 2007). Citizens, soldiers and other actors have the opportunity to enter the media circuit directly and publish first-hand testimonies of unfolding events on blogs, social network sites, outlets for citizen journalism 
on Web editions of newspapers, etc.

Non-professional visuals occupy a special position by representing the digital source materials most used and circulated by the mainstream news media (Andén-Papadopoulos and Pantti 2011, 12). They are also the only user-generated content to be presented in a manner similar to professionally produced content, particularly in connection with breaking news events (Pantti and Bakker 2009, 485). Amateur visuals challenge the controlled flow of information and overcome some of the former obstacles of war reporting, regarding access to areas of combat and the speed of transmission. The often dramatic, fragmented and shaky pictures of unfolding events taken by first-hand eyewitnesses give the news media the opportunity to obtain otherwise unobtainable information and gain access to otherwise inaccessible events. Obviously, this is particularly the case with coverage of conflict in countries with strict censorship and refusal of entry for foreign correspondents. In this way, amateur footage appears to depict conflict in an immediate, unfiltered and uncensored manner. The visuals may be said to belong to the "regime of truth" (Dovey 2000) associated with amateur aesthetics, and they add intimacy and potential audience identification to the news coverage. They also possess a strong value as documentary and even, occasionally, juridical evidence. However, amateur visuals inhabit the paradox of appearing authentic, and being difficult to authenticate. They are not easy to validate as source materials and involve a number of challenges concerning origin and narrative unity, just as they tend to be ambivalent, decontextualized and devoid of a stable meaning. Accordingly, it often proves difficult for the institutionalized media to extract a coherent and verifiable narrative from the information supplied by these sources.

Non-professional images generate and nourish (breaking) news stories by offering instant, unpolished 
and spectacular first-hand accounts, disseminated almost live and (from a media institutional perspective) produced at low or no cost (Pantti and Bakker 2009, 474). Citizens or eyewitnesses using digital technologies to enter the news stream seem increasingly to have adopted the media logic and the requirements of the news industry when it comes to providing news-valuable information, offering identification, drama, immediacy, authenticity, etc. With this emerging professionalization of amateur sources, the norms of journalism, particularly source criticism, are profoundly challenged. This is especially the case in conflict reporting because of the scarcity of alternative sources to verify the information, and the propensity of amateur sources to precede, undermine or contradict official statements or accounts (Mortensen 2011). Moreover, non-professional producers tend to perform a double role as participants in and eyewitnesses to the often violent and spectacular occurrences, and therefore present particularly framed accounts. Their identity may also be blurred or difficult to verify since they provide information under pseudonyms or remain anonymous, for reasons of personal safety or as a genre convention.

\section{Research Design: Content Analysis of the Coverage of the Death of Muammar Gaddafi}

The following analysis is based on a content analysis designed to answer the following research questions:

RQ1: Which types of sources are used in the news coverage of the death of Gaddafi?

RQ2: Which forms of interplay between amateur and elite sources are constructed by news media? This quantitative approach is supplemented with qualitative textual analysis because the double movement of reporting and trying to verify the information obtained from amateur sources 
constitutes the epicenter of the coverage-and of this analysis as well. By combining content analysis with a qualitative examination of the interplay between sources, we aim to meet some of the challenges outlined by Robinson et al. (2010) regarding case studies of digital media's impact on war reporting as to their random nature and lack of attention to the excellence of the reporting. The content analysis examines the coverage in two Danish national newspapers with high circulation but different reader and journalistic profiles based on the initial assumption that their coverage of the event would differ: the broadsheet Politiken (center-left political stance) and the tabloid B.T. (populist right-wing political stance), both in print and online. Later in the process, our focus shifted to common patterns surfacing in the coverage of both the broadsheet and the tabloid. Even though Danish media institutions have experienced increasing commercial demands, the Danish media system is, in the terms of Hallin and Mancini (2004), based in the democratic corporative model. A developed newspaper market, journalistic professionalization, public service obligations (broadcast) and indirect press subsidies (newspapers) (Strömbäck, Ørsten, and Aalberg 2008) characterize this model in general terms. Although the case examines the coverage of this international event in a specific national context, our intention is not to exemplify news coverage with particular "Danish" features. The conclusions have international relevance because of the international nature of the event and its journalistic representation.

The sample comprises the two weeks following Gaddafi's death (October 20, 2011 to November 2, 2011), when we assumed the coverage to be most extensive. This was confirmed by the sampling; the coverage ceased on October 29. We sampled the articles by means of Infomedia, an online-provider of access to Danish print and online media. At the outset, the sample consisted of all articles including 
the search words "Gaddafi" and "death", but the final sample was limited to articles focusing specifically on the event. Articles concerning the national and international political implications were omitted (e.g., NATO's discussions of withdrawing military forces or the future political situation in Libya). The study is thus based on a relatively narrow sampling of 124 articles in total (16 articles in Politiken, 47 articles on politiken.dk, 9 articles in B.T., 52 articles on bt.dk), and we therefore present the results in absolute numbers rather than in percentages.

A research assistant coded the articles based on a coding manual with variables concerning the manifest content (length, author, date, newspaper, etc.), the use of sources (different social categories, etc.), the thematic content and the illustrations/visuals as well as the relationship between visuals and editorial copy. We also mapped the origin of the visuals (social media, amateur photographer, press photographer) and the in/exclusion of source information about this origin. Further details about the variables are provided in the following analysis where relevant. We conducted an intercoder reliability test by recoding 20 units from the sample (16 per cent), five articles from each medium/platform (print/web, Politiken/B.T.). In most cases, the codings of the variables included in the codebook were consistent (1.00). However, the codings for "themes" (the three most dominant themes/topics in each article) and "sources" (up to the 10 most important sources in each article, including their social classification) presented 80-90 per cent consistency, which is an acceptable level of reliability (Lombard, Snyder-Duch, and Bracken 2002). 


\section{Elite Sources, Amateur Sources-and Metasourcing as a Journalistic Strategy}

The arrest and, soon thereafter, death of Muammar Gaddafi on 20 October 2011 constituted a major breaking news event to the global news media. Libya's political situation had been closely followed by news media after Gaddafi's regime targeted civilians in February 2011, and NATO decided to protect civilians by military operations the following month. In August, rebels declared that they had occupied Gaddafi's headquarters in Tripoli. Two months later, the former leader was killed in his native town, Sirte, also by rebels. To report Gaddafi's capture and killing, the news media described the content of the dramatic and spectacular incoming amateur visuals in great detail. The fragmented and turbulent images showed the dictator humiliated, assaulted and in different states of injury from the point of view of the agitated mob. As the pictures documented the event from changing angles and points in time, they provided diverging and even conflicting representations. The contribution by nonprofessionals should be seen in light of the limitations encountered by foreign journalists attempting to cover the turmoil in Libya (Allan 2013, 188).

In the following sections, we analyze the use of sources, source information and source materials in the news coverage of Gaddafi's death, focusing on the most dominant source categories and their respective roles and interaction in the media coverage.

Sources in the News Coverage of Gaddafi's Death: Major Findings - "Who" Not surprisingly, Gaddafi's capture and death is covered intensively on the day of the event and the following day (see Table 1). Forty-one articles are released online on 20 October as the news breaks, and an additional 42 articles are published in online and printed newspapers the following day. 
Table 1. Number of articles on the death of Gaddafi in the online and printed newspapers for October 20-29, 2011

\begin{tabular}{|l|r|r|r|r|r|r|r|r|r|r|r|}
\hline & $\begin{array}{c}20 . \\
10\end{array}$ & $\begin{array}{c}21.1 \\
0\end{array}$ & $\begin{array}{c}22.1 \\
0\end{array}$ & $\begin{array}{c}23.1 \\
0\end{array}$ & $\begin{array}{c}24.1 \\
0\end{array}$ & $\begin{array}{c}25.1 \\
0\end{array}$ & $\begin{array}{c}26.1 \\
0\end{array}$ & $\begin{array}{c}27.1 \\
0\end{array}$ & $\begin{array}{c}28.1 \\
0\end{array}$ & $\begin{array}{c}29.1 \\
0\end{array}$ & Total \\
\hline $\begin{array}{l}\text { Politiken } \\
\text { print }\end{array}$ & 0 & 6 & 3 & 3 & 1 & 1 & 1 & 0 & 0 & 1 & 16 \\
\hline $\begin{array}{l}\text { Politiken } \\
\text { web }\end{array}$ & 1 & 15 & 4 & 2 & 5 & 2 & 0 & 1 & 2 & 0 & 47 \\
\hline BT print & 0 & 6 & 2 & 1 & 0 & 0 & 0 & 0 & 0 & 0 & 9 \\
\hline BT web & 2 & 15 & 1 & 2 & 3 & 1 & 3 & 1 & 1 & 0 & 52 \\
\hline Total & 4 & 42 & 10 & 8 & 9 & 4 & 4 & 2 & 3 & 1 & 124 \\
\hline
\end{tabular}

The content was coded for the presence of the three most dominant themes in each article from a list of 25 specific themes, resulting in a total of 240 thematic codings. These codings were then regrouped into seven overall themes: (1) the event; (2) the after-play; (3) Gaddafi's life, family and supporters; (4) NATO military airplanes; (5) local and international reactions; (6) visuals from social media and meta-coverage; and (7) the political situation in Libya and internationally.

The main overall thematic focus of the coverage is the event (78 of 240 codings), defined as stories concerning Gaddafi's final hours and/or death. Uncertainty as to the actual sequence of events constitutes by far the most recurring single theme (40 codings) within this overall theme. The afterplay comprises the second most dominant overall theme, including forensic, political and juridical investigations into Gaddafi's death (58 codings), which gained media attention in the days following 
the event, October 21-25. Stories on reactions from the local and especially the international community (32 codings) mainly emerged on the day the story broke, and seem to represent a way for the news media to bring verified side-stories on the still not settled event.

The uncertainty foregrounded in the thematic codings also manifests itself in the extensive use of source actors or materials explicitly referred to or quoted in the articles: a total of 523 or on average four sources per article. More specifically, each article was coded for the presence of the up to 10 most dominant sources from the following list of social source categories: (1) Rebel; (2) Political representative of the National Transitional Council (NTC); (3) Gaddafi sympathiser; (4) Military representative (besides NTC); (5) Politician (besides NTC); (6) Official/spokesman; (7) Expert; (8) Journalist/correspondent; (9) News agency; (10) Media institution; (11) Amateur visuals from the capture of Gaddafi; (12) Written source material from social media; (13) Civilian; (14) Nongovernmental organization; (15) International organization (NATO, United Nations (UN), European Union (EU)) and (16) Others. Only seven articles include no sources at all, while the majority (80 articles of 124) contain between one and five sources. On the one hand, this indicates that the news media make an effort to comply with professional norms regarding the inclusion of as many relevant and available sources as possible, which would seem especially pertinent in light of the various unverified stories circulating immediately after the capture of Gaddafi. On the other hand, the abundance of sources may be interpreted as a sign of insecurity concerning the basic question of who and what qualify as relevant and reliable sources in this chaotic situation of plentiful source actors and materials volunteering their service.

At first glance, the coverage seems to be dominated by the military and political elites, who usually 
overshadow the news coverage of conflicts. Representing one in five sources (107 of 523), political delegates from the Libyan NTC comprise the prevalent category, while politicians (excluding NTC representatives) and international (political and/or military) institutions such as NATO, UN and EU represent one in five sources (53 and 40, respectively).

The media circuit also plays an important role as source. News agencies (e.g., Reuters, AFP) and other news institutions (e.g., Al Jazeera, Libyan television, CNN) represent the second and third most dominating source categories (63 and 62 of 523, respectively). Specific journalists or correspondents are also included as sources occasionally (13 of 523). In this way, one in four sources resides inside rather than outside a media institutional framework, and the mainstream news media often recirculate copy and illustrations from news agencies and other media institutions. Media institutional actors rely extensively on each other not only as sources of reference but also as sources of institutionalized legitimacy, even though they lack first-hand access to the event. This reflects the general tendency in contemporary journalism of including the perspectives of media institutions, commentators, correspondents and other media professionals in the news coverage as opposed to involving sources outside the media institutional realm (e.g., Allern and Blach- $\varnothing$ rsten 2011; Deuze 2008; Hjarvard 2010).

The coverage includes a third important group of sources, namely NTC rebels (44 of 523) and the visual materials produced by them (47 of 523). Their documentation of the event in the form of mobile footage and eyewitness accounts comes to play a crucial role in the media coverage but also in succeeding forensic and juridical investigations. As source actors, the rebels maneuver across the traditional divides between elites and non-elites, between observing and participating, and between 
being source actors and producers of source material. It is not clear whether they constitute political elite-interests communicating top-down, or should rather be considered loosely organized political opponents of the Gaddafi-regime getting their points of views across bottom-up. Moreover, they are participants in as well as eyewitnesses to the event, thereby blurring the boundaries between impartial documentation and active involvement. With another combination of hitherto disparate roles, they are simultaneously source actors and producers of source materials. From a qualitative perspective, the newspapers often juxtapose the accounts by participants/eyewitnesses with the visuals produced by the (same or other) participants/eyewitnesses in order to emphasize both identical and contradictory versions. Thus, as source actors the rebels exemplify that the roles, positions and agendas of non-conventional sources are not always transparent.

To summarize, on the face of it, the coverage is dominated by institutionalized elites in the form of political representatives and recognized media institutions. They are supplemented by NTC rebels, who constitute sources in-between elite and non-elite interests by representing a not formally institutionalized opposition to the official political and military regime.

Sources in the News Coverage of Gaddafi's Death: Major Findings- "How"

The uncertainty as to the course of the events also leaves its distinctive mark on the identifiability of sources, and how the newspapers use and credit them.

"Second-hand" sources-that is, sources referred to by other sources-frequently appear. For example, newspapers quoting a rebel quoted by Libyan television or by an international news agency. Second-hand sources comprise one in five sources (106 of 523). The use of second-hand sources is 
prevalent in all the analyzed media but most pronounced in online articles. In the 47 online articles at Politiken.dk, for example, news agencies are included as sources 34 times. This channeling of secondhand sources emphasizes that the news media do not possess first-hand access to the event by correspondents, photographers, etc., on location. In this way, the coverage becomes in part coverage of the coverage.

Another noteworthy result is that three in five sources are unnamed (314 of 523) and cannot be held responsible for the conveyed information and explication. This number covers mainly sources affiliated with the NTC-as either rebels taking military action or as political spokesmen and representatives taking political action. Both source categories have rather vague contours in terms of whether they represent an elite or non-elite perspective. The high percentage of unnamed or anonymous sources may be explained by ethical considerations, that is, the sources' personal safety or juridical interests in view of the controversial nature of the information or material. However, it may also point to the fact that the information flows from unconventional channels beyond the control of the media institutional framework, which therefore fails to gather information on or verify the sources' identities or agendas (see also Allan 2013, 185-200). Regardless of the cause, the weak identifiability of the sources challenges the transparency of the reporting.

To sum up, many of the actors given a voice hardly represent sources in the traditional journalistic sense of being providers of first-hand knowledge and name-given individuals or, at least, individuals whose identity is known to the reporting journalist. This tendency shows across the divide between elite and non-elite; the sources in question are often unnamed spokesmen of political interests or institutions (e.g., from NTC, EU or NATO), un-personified media institutions (Reuters, Al Jazeera) or 
random eyewitnesses to and/or participants in the event. Considering the news media's difficulties with accessing reliable first-hand sources, this finding is hardly surprising. Nonetheless, this strategy points to the way in which the news media gave high priority to reporting accounts from all kinds of sources (more or less) unfiltered in what might be designated a "report first and verify later" approach, thereby, apparently, setting aside most aspects of professional source criticism. At the same time, it indicates that the content or the revelation of information was more important than the identity of the sources providing the information, as is often the case with anonymous sources (Carlson 2011). The newspapers do not present a synthetized and balanced version of the facts, based on confirmed sources or source information. Instead, the coverage seems to a large extent to reflect the newspapers' processes of gathering information. This is symptomatic of the source-interaction in journalism brought about by digital media technologies.

\section{Sourcing and Metasourcing Amateur Visuals}

In the final part of the analysis, we divert our attention to a subject of particular interest in relation to sourcing and the challenges of digital media, namely the news media's reconstruction of information from a type of source material proliferating in recent years: amateur visuals. A qualitative analysis of how they are used by newspapers complements the quantitatively analysis and adds more nuances to the, at first glance, simple conclusion that elite sources dominate the coverage.

One in three articles explicitly refer to amateur visuals as news sources, but they also serve as content and illustrations. ${ }^{2}$ Even though amateur visuals are assigned value as documentary and juridical evidence, the news media encounter difficulties in naming and locating the original source and resort 
to metasourcing by including elite sources to comment on, challenge or interpret the amateur visuals and their implications.

According to some articles, the non-professional footage works as documentary evidence to undermine official statements concerning the sequence of events leading to the death of Gaddafi. For example, the article "Young Libyan Soldier: I Killed Gaddafi" ${ }^{3}$ published on Politiken.dk October 22 at 00:06 makes reference to a video circulated on the internet of and by a young rebel claiming he murdered Gaddafi. The article deploys this assumed confession as source information to undercut official statements from the NTC, asserting that Gaddafi was caught in crossfire during transportation after his capture. Similarly, another article published on bt.dk Friday October 21 at 04:16 "NTC: Gaddafi Was Not Killed Intentionally" refers to a video as counter evidence to a forensic report presented by the Libyan prime minister. The material is even considered valuable as proof in a legal context, e.g., according to the article “Gaddafi's Widow: Demands an Investigation of Gaddafi's Death", published on bt.dk on 21 October 2011 (23:50):

UN and several human rights watch organizations demand a full investigation into the events, which led to the death of the dictator. They fear he has been executed, after having been taken prisoner, which is a war crime ... The Libyan Transitional Council stated yesterday that Gaddafi was taken prisoner alive, but he was killed on his way to the hospital during an engagement between the rebels and Gaddafi supporters. The UN spokesman of human rights, Rupert Colville, is not convinced that this story stands up to scrutiny. "If you take the two videos together, it is rather disturbing, because you see someone who has been captured alive, and then you see the same person dead", he says to Reuters. 
Based, it seems, on careful examination of two amateur videos, the UN and human rights organizations demand an investigation into the killing of the dictator to determine if international conventions prohibiting the assassination of war prisoners have been violated. In this case, elites decode the visuals as evidence of Gaddafi's course of death.

However, referring to non-professional pictures far from guarantees transparency in the coverage.

The amateur visuals offered by the rebels are constantly verified, challenged and contradicted by elite sources and institutionalized media, just as chains of sourcing to other media institutions are recurrent. Elite sources are incorporated in what may be interpreted as the journalistic strategy of metasourcing in response to the amateur footage. Since their level of information regarding the specific event often equals that of the attentive media audience, the institutional legitimacy, expertise and experience of elite sources are used to comment on the validity of the amateur visuals and put them into a wider political or social perspective. Likewise, by crediting a number of news agencies or media institutions as sources, the articles attribute institutional authority to amateur visuals recorded by bystanders or participants, even though the newspapers merely recycle information and engage in self-referential performances.

When sourcing the origin of non-professional images, the newspapers rarely seem to disclose information about their producer or original distributive platform or their status as amateur footage. Instead, news agencies, especially AFP, EPA and Reuters, are credited as sources to 55 of all 147 illustrations in the coverage, and news agencies are listed as sources to 16 out of 25 stills from amateur videos published by the Danish newspapers in print and online. Establishing which facts and materials are provided by which sources often proves difficult because the articles do not necessarily 
position them in a hierarchy or specify how the different bits of information, e.g., text and visuals, are related. An example of the many layers of referencing appears in the article "Here's the Picture of Gaddafi Dying" on bt.dk, October 20 at 14:41, that is, approximately one hour after the story of Gaddafi's capture breaks:

A picture taken with a mobile camera shows the now deceased Muammar Gaddafi. It is send out by the French news agency AFP at this very moment. The global news agency Reuters is now confirming to the Guardian that the picture of colonel Gaddafi is genuine.

The amateur picture constitutes the story's center of attention as the (assumed) documentation of Gaddafi's death. At the same time, three media institutional sources are brought in to validate the image in the three brief sentences quoted above: the British newspaper The Guardian and the news agencies AFP and Reuters. The sense of urgency and immediacy associated with the amateur picture is emphasized by the deployment of the temporal markers "now" (twice) and "at this very moment." The time expressions are used once to point to the ongoing events ("the now deceased Muammar Gaddafi"), and twice to refer to the concurrent coverage of events by news agencies ("send out by the French news agency AFP at this very moment" and "[t]he global news agency Reuters is now"). The short time-span between the production of the mobile photo and the dissemination by institutionalized media makes the footage appear almost as live reporting from the event (Kristensen and Mortensen, 2014). However, even though the coverage takes its point of departure in the amateur picture, which ostensibly grants the viewer direct and near-live access to the scene of action, the newspapers deploy a chain of sources to legitimize its circulation. Although a number of institutions were sourced in relation to the amateur picture proclaimed to 
document Gaddafi's final moments, there appears to be disagreement in this and other articles with regard to the authenticity and genuineness of the visual source. While the headline and sub-headline say "Reuters Confirms - The Photo is Real. Here's the Picture of Gaddafi Dying", validated by the above-mentioned three media institutional sources, the caption of the photo posted directly below states "Is this the now deceased Muammar Gaddafi?", immediately bringing into doubt the veracity of the photo. Thus, the extensive use of sources paradoxically adds to the factual confusion and confirms that the coverage appears more like a front-stage editorial process than a well-balanced journalistic entity. This illustrates the media's propensity to refer to each other to verify what little may be verified by means of amateur pictures.

The articles' use of multiple and second-hand sources is further complicated by convergence or implicit collaborations between professional and non-professional producers, which are not communicated explicitly to the reader. In the example above, the caption credits the photo to AFP, while the text states that an amateur took the photo with a mobile camera. Adding to this ambiguity, the article fails to clarify that this intensely circulated photo of Gaddafi is in fact a professional photographer's photo of an amateur photographer's mobile screen. AFP made this information public in a press release on the very same day:

It was taken in Sirte by a rebel fighter using a mobile phone. AFP photographer Philippe Desmazes was able to take a photo of the mobile's screen a few minutes later and transmit the picture. (AFP 2011)

The professional photographer arrived after Gaddafi had been seized and removed from the scene, and gained exclusive access to the event through re-photographing and distributing the amateur 
footage. AFP identifies the original photographer as an anonymous "rebel fighter", i.e., by implication a participant, who may have a vested interest in depicting Gaddafi in a certain way and having this footage distributed globally. Different kinds of convergence or even implicit collaboration between professional and non-professional media actors are a pattern in a number of articles. Most commonly, the illustrations seem to originate from amateur videos, but are nonetheless credited to news agencies.

The qualitative analysis highlights the important role played by amateur visuals as sources, but also the challenge they represent to the professional sourcing of the news media. They are extremely relevant and carry great breaking news value due to their closeness to events, but they are also characterized by lack of authority, a high degree of uncertainty and limited opportunities for verification. Numerous sources with institutional legitimacy are included to counterbalance this missing validity. However, in the course of the editorial process, which mixes amateur visuals, elites and institutional news media, the origin of the visuals is lost, and source patterns become nontransparent.

\section{Conclusion: New Patterns of Metasourcing in War Journalism}

Digital media have multiplied the number and kinds of sources available to (war) journalism, and transformed the production and presentation of news in the current global and convergent media landscape. In this article, we have argued that one response by the mainstream news media to this development is to construct new forms of interplay between sources. This becomes particularly evident in the case of a breaking news event, such as the death of Muammar Gaddafi, because of two 
interrelated processes. Firstly, information comes from a variety of non-institutionalized sources (amateurs/participants/eyewitnesses), who more or less become the reporters of the event, while the institutionalized media, to some extent, are relegated to disseminating this multitude of visual fragments and bits of information rather than synthesize it into a coherent narrative. Secondly, speed appears at times to come before verification, and as a response to the constant flow of incoming unconfirmed information, various and even contradictory versions of an event are reported. We have further argued that a new approach to the performance of source criticism is instigated by this source inclusion. On the one hand, we have confirmed the traditional supremacy of elite sources in war and conflict reporting; they definitely outnumbered non-elite sources quantitatively. On the other hand, we have shown that elite sources and the re-cycling of information by self-referential media institutions mainly performed the more ritual function of confirming, explaining and commenting on the arrest and killing of the former dictator based on non-elite sources and first-hand accounts by eyewitnesses/participants. That is, sources who blur the boundaries of traditional distinctions between elite and non-elites as well as between amateurs and professionals. The political elites thus became a legitimizing tool for the news media in the coverage of the uncertain event, otherwise characterized by numerous second-hand and unnamed sources with ambiguous affiliations and roles. This strategy of legitimation is emphasized by news agencies and other news media constantly being brought in to counter-balance the amateur sources' lack of institutional legitimacy and transparency, e.g., when they are credited as producers of amateur visuals. Elite sources and selfreferential media positioned in a new role as metasources use their authority, expertise and experience to comment on the validity of the non-conventional sources, and put them into political 
and social perspective. While amateur sources bring authenticity, immediacy and proximity to war reporting by documenting events as they unfold, metasources are used as sources-on-other-sources. Metasourcing, the term introduced with this article, is related to the term metacoverage because both refer to the news media's self-referential practices. However, metacoverage represents a stronger form of self-referentiality; news stories characterized by metacoverage are typically centered on the role of news journalism and/or the communicative acts and strategies performed by military and political elites (e.g., Esser 2009; Esser and D’Angelo 2003; Esser and Spanier 2005; Mortensen 2012). Metasourcing constitutes a weaker form of self-referentiality in as much as the media and communicative processes are not necessarily the explicit subject of the story. Rather, metasourcing denotes the way in which elites, such as military and political actors or the institutionalized news media themselves, are drawn on extensively to validate other sources, thus foregrounding the professional routines and interests of the media circuit.

\section{Notes}

1. This article is the product of close collaboration between the two authors, and we are equally responsible for the content. Our names are listed alphabetically.

2. In total 147 visuals illustrate the 124 articles in the sample. Thirty-one visuals are video clips (six) or stills from video clips (25) produced by amateurs.

3. All Danish text is translated to English by the authors of this article. 


\section{References}

AFP. 2011. "World Exclusive: AFP Is the First News Agency to Transmit Photo of Dead Moamar Kadhafi." Press release, October 20. http://www.afp.com/en/agency/press-releasesnewsletter/world-exclusive-afp-first-news-agency-transmit-photo-dead-moamer-kadhafi. Allan, Stuart. 2013. Citizen Witnessing. Revisioning Journalism in Times of Crisis, Cambridge, MA: Polity Press.

Allern, Sigurd and Blach- $\varnothing$ rsten, Mark. 2011. The News Media As a Political Institution. A Scandinavian Perspective. Journalism Studies, 12(1): 92-105.

Andén-Papadopoulos, Kari and Pantti, Mervi, eds. 2011. Amateur Images and Global News, Bristol: Intellect Press.

Bergström, Annika. 2011. "The Scope of User-generated Content". In Journalists, Sources and Credibility: New Perspectives, Edited by: Franklin, Bob and Carlson, Matt. 167-181. New York: Routledge.

Carlson, Matt. 2011. "Whither Anonymity? Journalism and Unnamed Sources in a Changing Media Environment". In Journalists, Sources and Credibility: New Perspectives, Edited by: Franklin, Bob and Carlson, Matt. 37-48. New York: Routledge.

Carruthers, Susan L. 2011 [2000]. The Media at War. Basingstoke: Palgrave Macmillan.

Couldry, Nick. 2010. "New Online News Sources and Writer-gatherers". In New Media, Old News. Journalism and Democracy in the Digital Age, Edited by: Fenton, Natalie. 138-152. London: Sage. 
Davis, Aeron. 2009. Journalist-Source Relations, Mediated Reflexivity and the Politics of Politics. Journalism Studies, 10(2): 204-219. [Taylor \& Francis Online].

De Keyser, Jeroen, Karin Raeymaeckers, and Steve Paulussen. 2011. “Are Citizens Becoming Sources?" In Journalists, Sources and Credibility: New Perspectives, edited by Bob Franklin and Matt Carlson, 139-151. New York: Routledge.

Deuze, Mark. 2007. Media Work, London: Polity Press.

Deuze, Mark. 2008. Understanding Journalism As Newswork. Westminster Papers in Communication and Culture, 5(2): 4-23.

Dimitrova, Daniela V. and Strömbäck, Jesper. 2005. Mission Accomplished? Framing of the Iraq War in the Elite Newspapers in Sweden and the United States. Gazette: The International Journal for Communication Studies, 67(5): 399-417.

Dovey, John. 2000. Freakshow. First Person Media and Factual Television, London and Sterling, VA: Pluto Press.

Esser, Frank. 2009. Metacoverage of Mediated Wars. American Behavioral Scientist, 52(5): 709734.

Esser, Frank and D'Angelo, Paul. 2003. Framing the Press and the Publicity Process. A Content Analysis of Meta-coverage in Campaign 2000 Network News. American Behavioral Scientist, 46(5): 617-641.

Esser, Frank and Spanier, Bernd. 2005. News Management As News: How Media Politics Leads to Metacoverage. Journal of Political Marketing, 4(4): 27-57.

Franklin, Bob and Carlson, Matt, eds. 2011. Journalists, Sources and Credibility: New Perspectives, 
New York: Routledge.

Hallin, Daniel C. and Mancini, Paolo. 2004. Comparing Media Systems. Three Models of Media and Politics, West Nyack, NY: Cambridge University Press.

Hartley, Jannie. 2011. “Routinizing Breaking News Categories and Hierarchies in Danish Online Newsrooms." In Making Online News, vol. 2, edited by David Domingo and Chris Paterson, 7386. Oxford: Peter Lang.

Hjarvard, Stig. 2010. The Views of the News: The Role of Political Newspapers in a Changing Media Landscape. Northern Lights. Yearbook of Film and Media Studies, 8: 25-48.

Kristensen, Nete Nørgaard, and Mette Mortensen. 2014. “Non-professional Visuals Framing the News Coverage of the Death of Muammar Gaddafi". Mediating and Remediating Death, edited by Dorthe Refslund and Kjetil Sandvik. Burlington, VA: Ashgate.

Kristensen, Nete Nørgaard and Ørsten, Mark. 2007. Danish Media at War: The Danish Media Coverage of the Invasion of Iraq 2003. Journalism, 8(3): 323-344.

Kunelius, Risto and Renvall, Mika. 2010. Stories of a Public: Journalism and the Validity of Citizens' Testimonies. Journalism, 11(5): 515-529.

Lombard, Matthew, Snyder-Duch, Jennifer and Campanella Bracken, Cheryl. 2002. Content Analysis in Mass Communication. Human Communication Research, 28(4): 587-604.

Matheson, Donald and Allan, Stuart. 2009. Digital War Reporting, Cambridge: Polity Press. Mitchelstein, Eugenia and Boczkowski, Pablo J. 2009. Between Tradition and Change: A Review of Recent Research on Online News Production. Journalism, 10(5): 562-587.

Mortensen, Mette. 2011. When Citizen Photojournalism Sets the News Agenda: Neda Agha Soltan as 
a Web 2.0 Icon of Post-election Unrest in Iran. Global Media and Communication, 7(1): 4-16.

Mortensen, Mette. 2012. Metacoverage Taking the Place of Coverage: WikiLeaks As a Source for the Production of News in the Digital Age. Northern Lights. Film and Media Studies Yearbook, 10: 91-106.

Pantti, Mervi and Bakker, Piet. 2009. Misfortunes, Memories and Sunsets: Non-professional Images in Dutch News Media. International Journal of Cultural Studies, 12(5): 471-489.

Philips, Angela. 2010. “Old Sources: New Bottles”. In New Media, Old News. Journalism and Democracy in the Digital Age, Edited by: Fenton, Natalie. 87-101. London: Sage.

Robinson, Piers, Goddard, Peter, Parry, Katy, Murray, Craig and Taylor, Philip M. 2010. Pockets of Resistance, British News Media, War and Theory in the 2003 Invasion of Iraq, Manchester: Manchester University Press.

Schlesinger, Philip. 1990. "Rethinking the Sociology of Journalism". In Public Communication. The New Imperatives, Edited by: Ferguson, Marjorie. 61-83. London: Sage.

Seib, Philip, ed. 2007. New Media and the New Middle East, New York: Palgrave Macmillan.

Sjøvaag, Helle. 2011. "Amateur Images and Journalistic Authority". In Amateur Images and Global News, Edited by: Andén-Papadopoulos, Kari and Pantti, Mervi. 79-95. Bristol: Intellect Press. Strömbäck, Jesper, Ørsten, Mark and Aalberg, Toril, eds. 2008. Communicating Politics. Political Communication in the Nordic Countries, Gothenburg: NORDICOM.

Tuchman, Gaye. 1973. Making News by Doing Work: Routinizing the Unexpected. American Journal of Sociology, 79: 110-131.

Williams, Andy, Wardle, Clare and Wahl-Jorgensen, Karin. 2011. "The Limits of Audience 
Participation". In Journalists, Sources and Credibility: New Perspectives, Edited by: Franklin, Bob and Carlson, Matt. 152-166. New York: Routledge. 